(c) American Dairy Science Association, 2004.

\title{
Comparison of International Dairy Sire Evaluations from Meta-Analysis of National Estimated Breeding Values and Direct Analysis of Individual Animal Performance Records
}

\author{
C. Maltecca, ${ }^{1}$ A. Bagnato, ${ }^{1}$ and K. A. Weigel ${ }^{2}$ \\ ${ }^{1}$ VSA Department, University of Milan, Veterinary Medicine Via Celoria n², 20133 Milan, Italy \\ ${ }^{2}$ Department of Dairy Science, University of Wisconsin, 1675 Observatory Drive, Madison 53706
}

\begin{abstract}
Our objective was to assess the predictive ability of different methodologies for international genetic evaluation of milk yield and to determine the magnitude of differences in the resulting sire estimated breeding values (EBV). Data included first lactation records of $16,057,335$ Holstein-sired cows from 237,049 herds in 14 countries. Meta-analysis of national sire EBV using the multiple-trait across country evaluation (MACE) procedure, single-trait analysis of individual animal performance records, multiple-trait analysis of individual animal performance records, and borderless herd cluster model were compared by assessing predictive ability. Comparisons were based on root mean square error of sire EBV from a subset of records from cows calving between 1990 and 1995 and corresponding pedigree indices for sires that received their first genetic evaluations in 1996 or 1997. The number of bulls first evaluated in 1996 or 1997 that were in common between the top 25, 100, and 250 for pedigree index and the top 25,100 , and 250 for EBV were also determined for each method. Average root mean square error of prediction was $10.3 \mathrm{~kg}^{2}$ for the borderless single-trait model, 6.6 $\mathrm{kg}^{2}$ for the borderless herd cluster model, and $6.7 \mathrm{~kg}^{2}$ for both the borderless multiple-trait model and metaanalysis of national sire EBV using MACE. The mean numbers of common bulls among the top 25, 100, and 250 , respectively, when selected on pedigree index and subsequent EBV were 11, 48, and 154 for the borderless single-trait model; 16, 66, and 176 for the borderless multiple-trait model; 16,66 , and 178 for the borderless herd cluster model; and 15, 66, and 178 for meta-analysis of national sire EBV using MACE. Rank correlations between sire EBV from different models ranged from 0.77 for the single-trait borderless model and the metaanalysis using MACE to 0.92 for the borderless multiple-trait and the borderless herd cluster models.
\end{abstract}

Received January 30, 2004.

Accepted April 12, 2004.

Corresponding author: K. A. Weigel; e-mail: weigel@calshp.cals. wisc.edu.
(Key words: international sire evaluation, borderless model, genotype by environment interaction)

Abbreviation key: BCLU = borderless herd cluster model, DATAALL = full data set from cows calving in 1990-1997, DATA95 = subset of data from cows calving in 1990-1995, Interbull = International Bull Evaluation Service, LM305 = 305-d lactation model, MACE = multiple-trait across-country evaluation, MTPERF = multiple-trait analysis of individual animal performance records, $\mathbf{P I}=$ pedigree index, $\mathbf{R M S E}=$ root mean square error, RRTDM = random regression test-day model, STPERF = single-trait analysis of individual animal performance records.

\section{INTRODUCTION}

In recent years, international exchange of semen and embryos has become extremely common, such that dairy cattle improvement programs have become global in scope. The multiple-trait across country evaluation (MACE) procedure (Schaeffer, 1994) is currently used for routine international genetic evaluation of dairy sires. This procedure combines sire EBV from countries that participate in the International Bull Evaluation Service (Interbull), and it provides international EBV for each bull on the scale of each participating country. Although the MACE approach is convenient and computationally efficient, it lacks transparency (Interbull, which computes international sire evaluations, does not have access to the original performance records), and each country must be considered as a different production system.

In the past, direct analysis of test-day or lactation records from individual cows in participating countries was impossible because of computational limitations. However, increases in computer speed, memory, and storage capacity have made such large-scale analyses of field data possible. Several methods for direct evaluation of individual animal performance records have been proposed, including the "borderless" genetic evaluation concept suggested by Lohuis and Dekkers (1998). Lactation data from each country can be considered as 
a separate trait in a multiple-trait analysis, but true borderless evaluations consider the management and environmental conditions in each herd, regardless of country boundaries. Weigel and Rekaya (2000) and Zwald et al. (2003) assigned herds to production systems or "clusters" based on numerous variables that described the management, climate, and genetic potential of each herd. Other approaches to borderless evaluation of dairy sires have considered a reaction norm model (Fikse et al., 2003), in which the performance of each animal is predicted over a gradient of (1 or 2 ) key management variables, or meta-analysis of yield deviations from individual cows in participating countries (Canavesi et al., 2001). A review of these approaches was given by Weigel (2002).

The objectives of this paper were to compare the predictive ability of several competing methodologies for international genetic evaluation of milk yield and to determine the magnitude of differences in the resulting sire EBV.

\section{MATERIALS AND METHODS}

\section{Data}

Test-day milk records of first-parity, Holstein-sired cows calving from 1991 to 1997 in Australia, Belgium, Canada, Czech Republic, Finland, Germany, Hungary, Ireland, Israel, Italy, The Netherlands, New Zealand, South Africa, and the United States were used in this study. Each cow was required to have a test-day milk weight prior to $90 \mathrm{~d}$ postpartum, and records corresponding to sires with fewer than 5 progeny were discarded. Pedigrees for individual cows were obtained from each participating country, and pedigree data for sires were obtained from Interbull.

\section{Statistical Analysis}

Four alternative models for international dairy sire evaluation were considered: meta-analysis of national sire EBV using MACE, single-trait analysis of individual animal performance records (STPERF), multipletrait analysis of individual animal performance records (MTPERF), and a borderless herd cluster model (BCLU).

Meta-analysis of national sire $E B V$ using MACE. In the first approach, data from each country were analyzed independently using either a random regression test-day model (RRTDM) or a 305-d lactation model (LM305), depending on the method currently used for routine national genetic evaluation in that country (a list of countries and corresponding models is given in Table 2).
The RRTDM applied to data from each country had the following form:

$$
\begin{aligned}
\mathrm{y}_{\mathrm{ijk} l m n o}= & \mathrm{HTD}_{\mathrm{i}}+\mathrm{MF}_{\mathrm{j}}+\mathrm{AC}_{\mathrm{k}}+\sum_{\mathrm{t}=1}^{3} \beta_{\mathrm{lt}} \times \mathrm{f}_{\mathrm{lt}}+\sum_{\mathrm{t}=1}^{3} \beta_{\mathrm{mt}} \\
& \times \mathrm{a}_{\mathrm{mt}}+\sum_{\mathrm{t}=1}^{3} \beta_{\mathrm{nt}} \times \mathrm{p}_{\mathrm{nt}}+\mathrm{e}_{\mathrm{ijklmno}}
\end{aligned}
$$

where

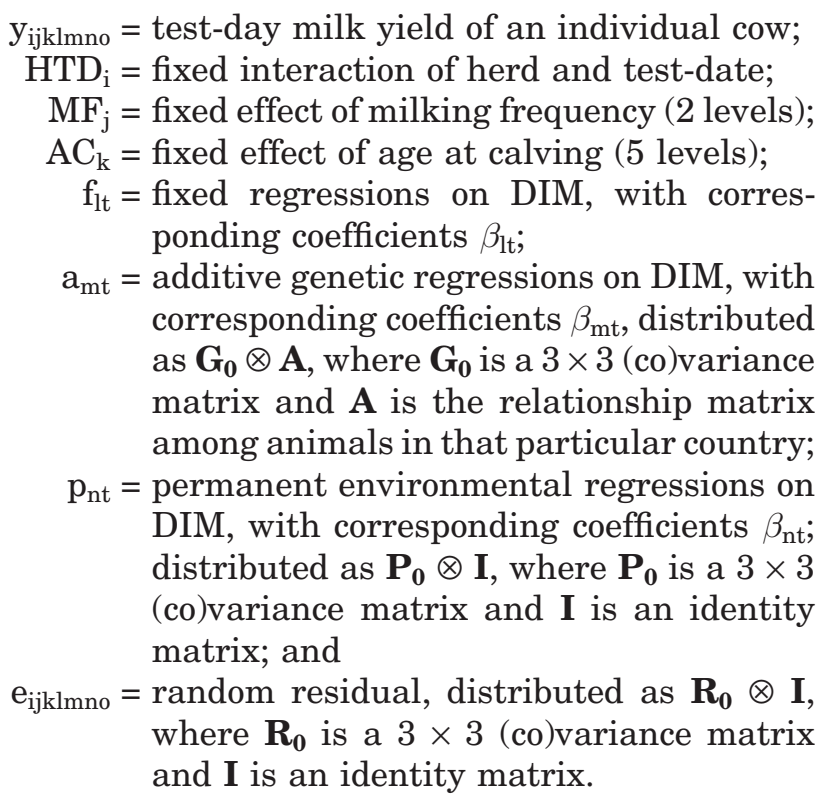

The regression coefficients $\beta_{\mathrm{lt}}, \beta_{\mathrm{mt}}$, and $\beta_{\mathrm{nt}}$ correspond to Legendre polynomials of the form:

$$
\begin{aligned}
& z_{1}=1, z_{2}=\sqrt{3 x}, \text { and } z_{3}=\sqrt{\frac{5}{4}}\left(3 x^{2}-1\right) \\
& \text { where } x=-1+2[(\text { DIM }-1) /(305-1)]
\end{aligned}
$$

Additive genetic, permanent environmental, and residual (co)variances for test-day milk yields were estimated from random subsets of herds using Gibbs sampling with a single chain of 100,000 samples and 10,000 samples discarded as burn-in. The BLUE and BLUP solutions were obtained by solving the mixed model equations conditionally on the estimated (co)variance components. The EBV for total 305-d milk yield were calculated as in Jamrozik et al. (2002).

The LM305 applied to data from each country had the following form:

$$
\mathrm{y}_{\mathrm{ijklm}}=\mathrm{HYS}_{\mathrm{i}}+\mathrm{MF}_{\mathrm{j}}+\mathrm{AC}_{\mathrm{k}}+\mathrm{a}_{\mathrm{l}}+\mathrm{e}_{\mathrm{ijklm}}
$$

where 
$\mathrm{y}_{\mathrm{ijklm}}=305-\mathrm{d}$ lactation milk yield of an individual cow in any participating country;

$\mathrm{HYS}_{\mathrm{i}}$ = fixed effect of herd-year-season of calving;

$\mathrm{MF}_{\mathrm{j}}$ = fixed effect of milking frequency (2 levels);

$\mathrm{AC}_{\mathrm{k}}=$ fixed effect of age at calving group (5 levels);

$\mathrm{a}_{1}=$ random additive genetic effect, distributed as $\mathbf{A} \sigma_{\mathbf{a}}{ }^{2}$, where $\mathbf{A}$ is the relationship matrix between animals in that particular country; and

$\mathrm{e}_{\mathrm{ijklm}}=$ random residual, distributed as $\mathbf{I} \sigma_{\mathbf{e}}{ }^{2}$, where $\mathbf{I}$ is an identity matrix.

The 305-d lactation yield of each animal was calculated as in Weigel et al. (2001).

Sire EBV from the RRTDM and LM305 models were subsequently de-regressed within country using the approach of Jairath et al. (1998), and sire variances were estimated within each country using an expectationmaximization-REML algorithm. The MACE procedure was then applied to de-regressed EBV from all countries simultaneously using genetic correlation estimates that are used in routine Interbull evaluations. Genetic groups for unknown parents were defined according to country of origin and year of birth.

STPERF. The second approach involved direct (simultaneous) analysis of the lactation records from all participating countries. Records from cows in different countries were considered as the same trait, ignoring potential genotype by environment interactions, such that all data were combined (pooled) and analyzed using a single-trait BLUP animal model:

$$
\mathrm{y}_{\mathrm{ijklm}}=\mathrm{HYS}_{\mathrm{i}}+\mathrm{MF}_{\mathrm{j}}+\mathrm{AC}_{\mathrm{k}}+\mathrm{a}_{\mathrm{l}}+\mathrm{e}_{\mathrm{ijklm}}
$$

where $\mathrm{y}_{\mathrm{ijklm}}, \mathrm{HYS}_{\mathrm{i}}, \mathrm{MF}_{\mathrm{j}}, \mathrm{AC}_{\mathrm{k}}, \mathrm{a}_{\mathrm{l}}$, and $\mathrm{e}_{\mathrm{ijklm}}$ were as defined previously for LM305. In other words, model STPERF was identical to model LM305, except that data from all countries were analyzed simultaneously, rather than independently. The milking frequency effect was applied across all countries, while the age at calving effect was nested within country.

MTPERF. In the third approach, lactation records from individual cows in all participating countries were also analyzed simultaneously. However, records from cows in different countries were considered as different traits, such that all possible genotype by country interactions were considered. The data were again pooled across countries, but this time a 14-trait BLUP animal model was used, and the model for each trait was as follows:

$$
\mathrm{y}_{\mathrm{ijklm}}=\mathrm{HYS}_{\mathrm{i}}+\mathrm{MF}_{\mathrm{j}}+\mathrm{AC}_{\mathrm{k}}+\mathrm{a}_{\mathrm{l}}+\mathrm{e}_{\mathrm{ijklm}}
$$

Table 1. Summary of data used in the present study (AUS = Australia, $\mathrm{BEL}=$ Belgium, $\mathrm{CAN}=$ Canada, $\mathrm{CZE}=$ Czech Republic, $\mathrm{DEU}=$ Germany, FIN = Finland, HUN = Hungary, IRL = Ireland, ISR = Israel, ITA = Italy, NLD = The Netherlands, NZL = New Zealand, USA = United States, and ZAF = South Africa).

\begin{tabular}{lcr}
\hline Country & Herds (no.) & Cows (no.) \\
\hline AUS & 9651 & 934,931 \\
BEL & 3028 & 75,656 \\
CAN & 14,447 & $1,062,664$ \\
CZE & 14,897 & 208,338 \\
DEU & 65,802 & $3,424,192$ \\
FIN & 14,176 & 137,067 \\
HUN & 1354 & 440,624 \\
IRL & 6453 & 173,215 \\
ISR & 1103 & 223,416 \\
ITA & 17,584 & $1,470,053$ \\
NLD & 26,340 & $1,510,595$ \\
NZL & 18,450 & $1,559,093$ \\
USA & 42,478 & $4,701,528$ \\
ZAF & 1286 & 135,963 \\
\hline
\end{tabular}

where $\mathrm{y}_{\mathrm{ijklm}}, \mathrm{HYS}_{\mathrm{i}}, \mathrm{MF}_{\mathrm{j}}, \mathrm{AC}_{\mathrm{k}}, \mathrm{a}_{\mathrm{l}}$, and $\mathrm{e}_{\mathrm{ijklm}}$ were as defined previously for LM305. In other words, the model for each of the 14 traits (countries) was the same as LM305, but all countries were evaluated simultaneously in a multiple-trait model. Covariance components were estimated from a sample of 500,000 animals, where sampling of the herds was as in Weigel and Zwald (2002).

$\boldsymbol{B C L} \boldsymbol{U}$. Herds were grouped into unique production systems using cluster analysis. Clustering of herds was performed according to Zwald et al. (2003), using the following descriptive herd characteristics: peak yield, temperature, herd size, and days to peak. All of the descriptors were calculated according to Zwald et al. (2003).

Covariance components were estimated from a sample of 500,000 animals. Each "cluster" of herds was treated as a separate trait in a 4-trait BLUP animal model where the model for each trait was as follows:

Table 2. Grouping of countries according to type of national genetic evaluation system $($ AUS $=$ Australia, $\mathrm{BEL}=$ Belgium, $\mathrm{CAN}=$ Canada, $\mathrm{CZE}=$ Czech Republic, DEU = Germany, FIN = Finland, HUN = Hungary, IRL = Ireland, ISR = Israel, ITA = Italy, NLD = The Netherlands, NZL $=$ New Zealand, USA $=$ United States, and ZAF $=$ South Africa).

\begin{tabular}{lll}
\hline RRTDM $^{1}$ & & LM305 $^{2}$ \\
\hline AUS & BEL & \\
CAN & CZE & ITA \\
DEU & HUN & USA \\
FIN & IRL & ZAF \\
NLD & ISR & \\
NZL & & \\
\hline
\end{tabular}

${ }^{1} \mathrm{RRTDM}=$ Random regression test-day model.

${ }^{2} \mathrm{LM} 305$ = 305-d lactation model. 
Table 3. Heritabilities of lactation milk yield in each country using each of 4 four competing models (AUS = Australia, BEL = Belgium, CAN = Canada, $\mathrm{CZE}=$ Czech Republic, DEU = Germany, FIN = Finland, HUN = Hungary, IRL $=$ Ireland, ISR $=$ Israel, ITA $=$ Italy, NLD $=$ The Netherlands, NZL $=$ New Zealand, USA = United States, and ZAF = South Africa).

\begin{tabular}{|c|c|c|c|c|c|c|c|c|c|c|c|c|c|c|}
\hline Model & AUS & BEL & CAN & $\mathrm{CZE}$ & DEU & FIN & HUN & IRL & ISR & ITA & NLD & NZL & USA & $\mathrm{ZAF}$ \\
\hline RRTDM $^{1}$ & 0.30 & - & 0.28 & - & 0.27 & 0.24 & - & 一 & 一 & - & 0.27 & 0.28 & - & - \\
\hline LM $305^{2}$ & - & 0.33 & - & 0.34 & - & - & 0.24 & 0.36 & 0.34 & 0.33 & - & - & 0.32 & 0.30 \\
\hline STPERF $^{3}$ & 0.33 & 0.3 & 0.33 & 0.33 & 0.33 & 0.33 & 0.33 & 0.33 & 0.33 & 0.33 & 0.33 & 0.33 & 0.33 & 0.3 \\
\hline MTPERF $^{4}$ & 0.33 & 0.27 & 0.33 & 0.33 & 0.33 & 0.23 & 0.25 & 0.35 & 0.31 & 0.32 & 0.32 & 0.32 & 0.30 & 0.33 \\
\hline & & \multicolumn{2}{|c|}{ Cluster 1} & & & \multicolumn{2}{|c|}{ Cluster 2} & & \multicolumn{3}{|c|}{ Cluster 3} & & \multicolumn{2}{|c|}{ Cluster 4} \\
\hline $\mathrm{BCLU}^{5}$ & & \multicolumn{2}{|r|}{0.33} & & & \multicolumn{2}{|c|}{0.35} & & \multicolumn{3}{|c|}{0.31} & & \multicolumn{2}{|c|}{0.29} \\
\hline
\end{tabular}

${ }^{1} \mathrm{RRTDM}=$ random regression test-day model.

${ }^{2}$ LM305 = 305-d lactation model.

${ }^{3}$ STPERF $=$ single-trait analysis of individual animal performance records.

${ }^{4} \mathrm{MTPERF}=$ multiple-trait analysis of individual animal performance records.

${ }^{5} \mathrm{BCLU}=$ borderless herd cluster model.

$$
\mathrm{y}_{\mathrm{ijklm}}=\mathrm{HYS}_{\mathrm{i}}+\mathrm{MF}_{\mathrm{j}}+\mathrm{AC}_{\mathrm{k}}+\mathrm{a}_{\mathrm{l}}+\mathrm{e}_{\mathrm{ijklm}}
$$

where $\mathrm{y}_{\mathrm{ijklm}}, \mathrm{HYS}_{\mathrm{i}}, \mathrm{MF}_{\mathrm{j}}, \mathrm{AC}_{\mathrm{k}}, \mathrm{a}_{\mathrm{l}}$, and $\mathrm{e}_{\mathrm{ijk} \mathrm{km}}$ were as defined previously for LM305. Therefore, the model for each of the 4 traits (clusters) was the same as LM305, and all clusters were evaluated simultaneously in a multiple-trait model.

\section{Model Validation}

The predictive ability of the 4 models described previously was compared as follows. Sire breeding values were estimated within a subset of records from cows calving from 1990 to 1995 (DATA95) using MACE, STPERF, MTPERF, or BCLU. The pedigree index (PI) for all sires that received their first genetic evaluation in 1996 or 1997 was calculated from the EBV of their parents in DATA95. The 4 competing models were compared based on root mean square error (RMSE), aver- aged across sires and countries, of the difference between sires' PI obtained with DATA95 and their EBV obtained from the full data set (DATAALL). In the BCLU model, sire EBV for each country were calculated by weighting the EBV from each cluster by the proportion of herds belonging to that cluster, as in Fikse (2002).

\section{RESULTS AND DISCUSSION}

A summary of the data used in this study is shown in Table 1. The number of animals ranged from 75,656 in Belgium to 4,701,528 in the United States, and the number of herds ranged from 1103 in Israel to 65,802 in Germany. The mean number of first-parity animals per herd ranged from 10 in Finland to 325 in Hungary.

Table 2 summarizes the types of national genetic evaluation systems used in the 14 participating countries. Six countries (Australia, Canada, Finland, Ger-

Table 4. Genetic correlations between countries in the multiple-trait analysis of individual animal performance records model $(\mathrm{AUS}=$ Australia, $\mathrm{BEL}=$ Belgium, $\mathrm{CAN}=$ Canada, $\mathrm{CZE}=$ Czech Republic, $\mathrm{DEU}=$ Germany, FIN = Finland, HUN = Hungary, IRL = Ireland, ISR = Israel, ITA = Italy, NLD = The Netherlands, NZL = New Zealand, USA = United States, and ZAF = South Africa).

\begin{tabular}{|c|c|c|c|c|c|c|c|c|c|c|c|c|c|}
\hline & BEL & CAN & CZE & DEU & FIN & HUN & IRL & ISR & ITA & NLD & NZL & USA & $\mathrm{ZAF}$ \\
\hline AUS & 0.85 & 0.83 & 0.86 & 0.85 & 0.87 & 0.76 & 0.92 & 0.79 & 0.82 & 0.82 & 0.98 & 0.84 & 0.83 \\
\hline BEL & & 0.94 & 0.86 & 0.90 & 0.85 & 0.80 & 0.82 & 0.90 & 0.91 & 0.92 & 0.84 & 0.96 & 0.86 \\
\hline CAN & & & 0.83 & 0.92 & 0.87 & 0.86 & 0.84 & 0.86 & 0.94 & 0.96 & 0.88 & 0.94 & 0.86 \\
\hline CZE & & & & 0.87 & 0.80 & 0.78 & 0.81 & 0.81 & 0.82 & 0.89 & 0.82 & 0.85 & 0.90 \\
\hline DEU & & & & & 0.82 & 0.78 & 0.83 & 0.85 & 0.92 & 0.92 & 0.90 & 0.93 & 0.85 \\
\hline FIN & & & & & & 0.79 & 0.88 & 0.86 & 0.85 & 0.83 & 0.84 & 0.88 & 0.80 \\
\hline HUN & & & & & & & 0.76 & 0.82 & 0.83 & 0.84 & 0.77 & 0.84 & 0.80 \\
\hline IRL & & & & & & & & 0.84 & 0.83 & 0.85 & 0.93 & 0.84 & 0.80 \\
\hline ISR & & & & & & & & & 0.84 & 0.83 & 0.83 & 0.89 & 0.79 \\
\hline ITA & & & & & & & & & & 0.92 & 0.86 & 0.94 & 0.84 \\
\hline NLD & & & & & & & & & & & 0.88 & 0.93 & 0.86 \\
\hline NZL & & & & & & & & & & & & 0.90 & 0.91 \\
\hline USA & & & & & & & & & & & & & 0.90 \\
\hline
\end{tabular}


Table 5. Number and herds and cows from each country corresponding to each cluster in the borderless herd cluster model $(\mathrm{AUS}=$ Australia, $\mathrm{BEL}=$ Belgium, $\mathrm{CAN}=$ Canada, $\mathrm{CZE}=$ Czech Republic, $\mathrm{DEU}=$ Germany, FIN = Finland, HUN = Hungary, IRL = Ireland, ISR = Israel, ITA = Italy, NLD = The Netherlands, NZL = New Zealand, USA = United States, and ZAF = South Africa).

\begin{tabular}{|c|c|c|c|c|c|c|c|c|}
\hline \multirow[b]{2}{*}{ Country } & \multicolumn{2}{|c|}{ Cluster 1} & \multicolumn{2}{|c|}{ Cluster 2} & \multicolumn{2}{|c|}{ Cluster 3} & \multicolumn{2}{|c|}{ Cluster 4} \\
\hline & Herds & Cows & Herds & Cows & Herds & Cows & Herds & Cows \\
\hline AUS & 3281 & 494,585 & 201 & 126,032 & 129 & 13,568 & 6040 & 300,746 \\
\hline BEL & 103 & 10,602 & 5 & 2893 & 57 & 6316 & 2863 & 55,845 \\
\hline CAN & 4461 & 413,220 & 149 & 85,402 & 1167 & 103,255 & 8670 & 460,787 \\
\hline $\mathrm{CZE}$ & 202 & 6781 & 232 & 92,083 & 42 & 2931 & 14,421 & 106,543 \\
\hline DEU & 6020 & 427,812 & 1338 & 927,812 & 9942 & 566,252 & 48,502 & $1,502,316$ \\
\hline FIN & 407 & 7324 & 6 & 2685 & 661 & 57,199 & 13,102 & 69,859 \\
\hline HUN & 164 & 14,562 & 546 & 385,594 & 87 & 20,805 & 557 & 19,663 \\
\hline IRL & 202 & 20,311 & 62 & 40,225 & 221 & 9963 & 5968 & 102,716 \\
\hline ISR & 850 & 135,462 & 162 & 80,225 & 67 & 7303 & 24 & 426 \\
\hline ITA & 5609 & 501,085 & 935 & 469,158 & 700 & 69,789 & 10,340 & 430,021 \\
\hline NLD & 1588 & 165,209 & 334 & 145,209 & 4574 & 308,709 & 19,844 & 891,468 \\
\hline NZL & 1284 & 93,241 & 251 & 173,247 & 15,959 & $1,229,928$ & 956 & 62,677 \\
\hline USA & 19,682 & $2,163,644$ & 1408 & $1,000,102$ & 2334 & 251,301 & 19,054 & $1,286,481$ \\
\hline $\mathrm{ZAF}$ & 271 & 19,654 & 126 & 58,589 & 375 & 31,779 & 514 & 25,941 \\
\hline
\end{tabular}

many, The Netherlands, and New Zealand) used some form of test-day model. Eight countries (Belgium, Czech Republic, Hungary, Ireland, Israel, Italy, United States, and South Africa) used an LM305.

Table 3 summarizes the estimated heritability parameters from the present study corresponding to each country and each genetic evaluation model. Heritability estimates for the RRTDM were calculated as the average of heritability estimates throughout the lactation. Within-country heritability estimates ranged from 0.24 in Finland and Hungary to 0.36 in Ireland. Heritability estimates from the MTPERF and BCLU models were consistent with estimates of Weigel et al. (2001) and Zwald et al. (2003). Heritability estimates from the within-country models (LM305 and RRTDM) were generally similar to estimates from MTPERF, with the largest differences corresponding to Belgium (0.06) and Canada, Germany, and New Zealand (0.05).

Estimated genetic correlations from the MTPERF model, shown in Table 4, were similar to the parameters used by Interbull for routine international dairy sire evaluations. Estimates between certain pairs of countries were relatively low, such as Australia and Hungary (0.76), Australia and Israel (0.79), Czech Republic and Hungary (0.78), Finland and Hungary (0.79), Germany and Hungary (0.78), Hungary and Ireland (0.76),

Table 6. Genetic correlations between clusters (production systems) in the borderless herd cluster model.

\begin{tabular}{lccc}
\hline & Cluster 2 & Cluster 3 & Cluster 4 \\
\hline Cluster 1 & 0.92 & 0.91 & 0.86 \\
Cluster 2 & & 0.89 & 0.88 \\
Cluster 3 & & & 0.87 \\
\hline
\end{tabular}

Hungary and New Zealand (0.77), and Israel and South Africa (0.79). On the other hand, estimates between some pairs of countries approached unity, such as Australia and New Zealand (0.98), Belgium and Canada (0.94), Belgium and the United States (0.96), Canada and Italy (0.94), Canada and the United States (0.94), Canada and The Netherlands (0.96), Germany and the United States (0.93), Ireland and New Zealand (0.93), Italy and the United States (0.94), and The Netherlands and the United States (0.93).

Table 5 shows the number and herds and cows from each country that were included in each of the 4 clusters (production environments) in the BCLU model. Cluster 1 was composed primarily of medium-sized herds from Australia, Canada, Italy, and the United States. Cluster 2 included mainly herds from Germany, Hungary, Italy, and the United States and was characterized by large herd size. Cluster 3 was characterized by low peak yield and short days to peak yield and consisted largely of herds in Australia, Germany, and New Zealand. Cluster 4 included mostly small herds, the majority of which were from the United States, Canada, Germany, and The Netherlands.

Table 6 shows estimated genetic correlations among the 4 clusters of herds obtained from the BCLU model. Estimates ranged from 0.86 between clusters 1 and 4 to 0.92 between clusters 1 and 2 . These estimates tend to reflect the similarity, or lack thereof, between the management and climate conditions present in herds that were grouped into different clusters or production systems.

Table 7 shows the mean RMSE between PI from DATA95 and subsequent EBV from DATAALL for each of the 14 countries. The BCLU model provided slightly 
Table 7. Average root mean square error (RMSE; $\mathrm{kg}^{2}$ ) for sires that received their first genetic evaluation in 1996 or 1997 in each country under each competing model, where RMSE was calculated as the squared difference between pedigree index from 1990 to 1995 data and EBV from 1990 to 1997 data (AUS = Australia, BEL = Belgium, CAN = Canada, CZE = Czech Republic, DEU = Germany, FIN = Finland, HUN = Hungary, IRL = Ireland, ISR = Israel, ITA = Italy, NLD = The Netherlands, NZL = New Zealand, USA = United States, and ZAF $=$ South Africa).

\begin{tabular}{|c|c|c|c|c|c|c|c|c|c|c|c|c|c|c|c|}
\hline Model & AUS & BEL & CAN & $\mathrm{CZE}$ & DEU & FIN & HUN & IRL & ISR & ITA & NLD & NZL & USA & $\mathrm{ZAF}$ & Mean \\
\hline MACE $^{1}$ & 6.9 & 7.1 & 6.8 & 7.2 & 6.7 & 6.6 & 6.8 & 7.3 & 6.6 & 6.4 & 6.4 & 6.9 & 6.3 & 6.4 & 6.74 \\
\hline MTPERF $^{2}$ & 6.4 & 7.2 & 6.9 & 7.0 & 6.8 & 6.8 & 6.9 & 7.0 & 6.8 & 6.4 & 6.6 & 6.4 & 6.4 & 6.8 & 6.74 \\
\hline $\mathrm{BCLU}^{3}$ & 6.3 & 7.0 & 6.7 & 6.9 & 6.5 & 6.6 & 6.7 & 7.0 & 6.8 & 6.3 & 6.6 & 6.3 & 6.4 & 6.8 & 6.63 \\
\hline STPERF $^{4}$ & 10.3 & 10.3 & 10.3 & 10.3 & 10.3 & 10.3 & 10.3 & 10.3 & 10.3 & 10.3 & 10.3 & 10.3 & 10.3 & 10.3 & 10.3 \\
\hline
\end{tabular}

${ }^{1} \mathrm{MACE}=$ Multiple-trait across-country evaluation.

${ }^{2}$ MTPERF = Multiple-trait analysis of individual animal performance records.

${ }^{3} \mathrm{BCLU}=$ Borderless herd cluster model.

${ }^{4} \mathrm{STPERF}=$ Single-trait analysis of individual animal performance records.

lower RMSE (hence, better agreement between PI from DATA95 and EBV from DATAALL) than the MTPERF and MACE models, which, in turn, had much smaller RMSE than the STPERF model. This analysis provides strong evidence that ignoring potential genotype by environment interactions, as was the case in model STPERF, reduces the accuracy of sire EBV in international genetic evaluations. Furthermore, it indicates that the BCLU model is very competitive, in terms of accuracy of sire EBV, with the MACE and MTPERF approaches. The RMSE between sire EBV and PI in each of the 4 clusters was 6.1 for cluster $1,6.5$ for cluster $2,6.7$ for cluster 3 , and 7.2 for cluster 4 .

Table 8 shows the number of sires with their first genetic evaluation in 1996 or 1997 that were in common between the top 25,100 , and 250 for PI in DATA95 and the top 25,100 , and 250 for EBV in DATAALL under each of the 4 competing models. Results for models BCLU, MTPERF, and MACE were similar, indicating that ability of these methods to identify elite sires is likely to be similar, and any of these methods is likely to yield more satisfactory results than model STPERF. The numbers of common bulls between PI and EBV for the 4 clusters with the BCLU model were 18, 70, and 184 for cluster $1 ; 16,68$, and 181 for cluster $2 ; 16,66$, and 179 for cluster 3; and 13, 60, and 168 for cluster 4 , respectively, for the highest ranking 25,100 , and 250 bulls.

Spearman rank correlations between sire PI and EBV in each of the 4 models are shown in Table 9. Correla-

Table 8. Number of bulls first evaluated in 1996 or 1997 that were in common between the top 25, 100, and 250 for pedigree index and the top 25, 100, and 250 for sire EBV, respectively, in each country using each method (AUS = Australia, BEL = Belgium, CAN = Canada, $\mathrm{CZE}=$ Czech Republic, DEU = Germany, FIN = Finland, HUN = Hungary, IRL = Ireland, ISR = Israel, ITA = Italy, NLD = The Netherlands, NZL $=$ New Zealand, USA = United States, and ZAF = South Africa).

\begin{tabular}{|c|c|c|c|c|c|c|c|c|c|c|c|c|c|c|c|}
\hline Model & AUS & BEL & CAN & CZE & DEU & FIN & HUN & IRL & ISR & ITA & NLD & NZL & USA & $\mathrm{ZAF}$ & Mean \\
\hline $\mathrm{MACE}^{1}$ & 16 & 16 & 17 & 13 & 17 & 13 & 15 & 16 & 15 & 16 & 15 & 15 & 17 & 15 & 15.4 \\
\hline $\mathrm{BCLU}^{3}$ & 18 & 16 & 16 & 13 & 15 & 14 & 14 & 16 & 16 & 16 & 16 & 18 & 18 & 14 & 15.7 \\
\hline STPERF $^{4}$ & 11 & 11 & 11 & 11 & 11 & 11 & 11 & 11 & 11 & 11 & 11 & 11 & 11 & 11 & 11 \\
\hline MACE & 65 & 69 & 70 & 62 & 73 & 59 & 61 & 66 & 65 & 68 & 67 & 67 & 70 & 65 & 66.2 \\
\hline STPERF & 48 & 48 & 48 & 48 & 48 & 48 & 48 & 48 & 48 & 48 & 48 & 48 & 48 & 48 & 48 \\
\hline MACE & 178 & 176 & 185 & 165 & 191 & 162 & 177 & 172 & 176 & 184 & 175 & 182 & 195 & 170 & 177.7 \\
\hline MTPERF & 182 & 172 & 180 & 163 & 175 & 167 & 175 & 181 & 168 & 172 & 171 & 189 & 186 & 176 & 175.5 \\
\hline BCLU & 185 & 170 & 181 & 163 & 186 & 165 & 176 & 178 & 177 & 176 & 181 & 190 & 189 & 176 & 178.1 \\
\hline STPERF & 154 & 154 & 154 & 154 & 154 & 154 & 154 & 154 & 154 & 154 & 154 & 154 & 154 & 154 & 154 \\
\hline
\end{tabular}

${ }^{1} \mathrm{MACE}=$ Multiple-trait across-country evaluation.

${ }^{2}$ MTPERF = Multiple-trait analysis of individual animal performance records.

${ }^{3} \mathrm{BCLU}=$ Borderless herd cluster model.

${ }^{4} \mathrm{STPERF}=$ Single-trait analysis of individual animal performance records. 
Table 9. Spearman rank correlations between models for pedigree index calculated from data of cows calving in 1990 to 1995 (above diagonal) and estimated breeding values calculated from data of cows calving in 1990 to 1997 (below diagonal).

\begin{tabular}{lllll}
\hline & MACE $^{1}$ & STPERF $^{2}$ & MTPERF $^{3}$ & BCLU $^{4}$ \\
\hline MACE & & 0.77 & 0.86 & 0.85 \\
STPERF & 0.78 & & 0.77 & 0.78 \\
MTPERF & 0.84 & 0.78 & & 0.92 \\
BCLU & 0.85 & 0.77 & 0.92 & \\
\hline
\end{tabular}

${ }^{1} \mathrm{MACE}=$ Multiple-trait across-country evaluation.

${ }^{2}$ STPERF $=$ Single-trait analysis of individual animal performance records.

${ }^{3}$ MTPERF $=$ Multiple-trait analysis of individual animal performance records.

${ }^{4} \mathrm{BCLU}=$ Borderless herd cluster model.

tions were highest (0.92) between PI and EBV from models BCLU and MTPERF, and correlations between these models and MACE were moderate (0.84 to 0.86). Correlations between PI and EBV from model STPERF and the other 3 models were considerably lower $(0.77$ to 0.78 ).

\section{CONCLUSIONS}

The MACE methodology for international genetic evaluation of dairy sires has been used in practice (with various improvements) for nearly a decade. Alternatives based on joint analysis of individual animal performance records have not been considered until recently because of computational limitations. Because of advances in speed, memory, storage, and affordability of computers, alternative models such as STPERF, MTPERF, and BCLU are now possible.

Based on the results of this study, as well as intuitive knowledge about differences in management, nutrition, and climate between countries, the assumption that milk production can be considered as the same trait in all countries appears to be too simplistic. The performance of relatives in different production systems, whether accommodated by the MACE, MTPERF, or BCLU model, appears to provide a valuable contribution to the accuracy of sire EBV in each country.

Considering each country as a separate trait (model MTPERF) or clustering herds based on management conditions (model BCLU) seems to offer predictive ability similar to that of meta-analysis of national sire EBV using MACE. Although sire rankings will differ slightly among these 3 approaches, it appears that other factors, such as quality of the performance data or accuracy of the pedigree information from each country, may have a larger impact on the accuracy of genetic predictions than the choice of methodologies for international sire evaluation. The MACE approach offers clear advantages in computational feasibility, although it lacks "transparency," because actual daughter performance records are unavailable to those responsible for international sire evaluations (hence, Interbull cannot validate the raw data from each country). Both the MACE and MTPERF approaches offer ease of interpretation, because international sire EBV will have the same genetic base, scale, and units of measurement as national sire EBV. The BCLU model is more intuitively appealing because production systems are defined according to management practices and climate conditions rather than arbitrary political boundaries. However, additional education of end-users would be necessary if BCLU were implemented because sire EBV for different (types of) herds within each country would differ.

\section{REFERENCES}

Canavesi, F., D. Boichard, V. Ducroq, N. Gengler, G. De Jong, and Z. Liu. 2001. Production traits European joint evaluation (PROTEJE). Interbull Bull. 27:32-34.

Fikse, W. F. 2002. Comparison between using performance records and national breeding values as input into international genetic evaluation. Advances in International Genetic Evaluation Procedures of Dairy Cattle. Ph.D. Diss., Acta Universitatis Agricolturae Sueciae Agraria.

Fikse, W. F., R. Rekaya, and K. A. Weigel. 2003. Genotype × environment interaction for milk production in Guernsey cattle. J. Dairy Sci. 86:1821-1827.

Jairath, L., J. C. M. Dekkers, L. R. Schaeffer, Z. Liu, E. B. Burnside, and B. Kolstad. 1998. Genetic evaluation for herd life in Canada. J. Dairy Sci. 81:550-562.

Jamrozik, J., L. R. Schaeffer, and K. A. Weigel. 2002. Genetic evaluation of bulls and cows with single- and multiple-country test-day models. J. Dairy Sci. 85:1617-1622.

Lohuis, M. M., and J. C. M. Dekkers. 1998. Merit of borderless evaluations. Proc. 6th World Congr. Genet. Appl. Livest. Prod., Armidale, Australia XXVI:169-172.

Schaeffer, L. R. 1994. Multiple-country comparison of dairy sires. J. Dairy Sci. 77:2671-2678.

Weigel, K. A. 2002. Prediction of international breeding values of dairy sires using individual animal performance records. Proc. 7th World Congr. Genet. Appl. Livest. Prod. Montpellier, France. 29:83-90.

Weigel, K. A., and R. Rekaya. 2000. A multiple-trait herd cluster model for international dairy sire evaluation. J. Dairy Sci. 83:815-821.

Weigel, K. A., and N. R. Zwald. 2002. Selection and grouping of herds in international genetic evaluation of daughter performance records. Interbull Bull. 29:7-11.

Weigel, K. A., N. R. Zwald, R. Rekaya, and W. F. Fikse. 2001. International genetic evaluation of dairy sires using a multiple-trait model with individual performance records. J. Dairy Sci. 84:2789-2795.

Zwald, N. R., K. A. Weigel, W. F. Fikse, and R. Rekaya. 2003. Application of a multiple-trait herd cluster model for genetic evaluation of dairy sires from seventeen countries. J. Dairy Sci. 86:376-382. 